\title{
Effect of Self Care Protocol for Colostomy Patients on Peristomal Skin Complications
}

\section{Aml Mohamed Mohamed ${ }^{\mathbf{1}}$, Manal Hamed Mahmoud ${ }^{2}$ and Rawia Ali Ibrahim ${ }^{\mathbf{3}}$}

(1) Nursing specialist at Quesna Central Hospital, Egypt, (2) Professor of Medical Surgical Nursing - Faculty of Nursing- Benha University, Egypt and (3) Lecturer of Medical Surgical Nursing - Faculty of Nursing- Benha University, Egypt

\begin{abstract}
Background: Colostomy is a surgically created opening in the abdomen in which a piece of the colon is brought outside the abdominal wall to create a stoma through which digested food passes into an external pouching system. Aim of study: Was to evaluate the effect of educational self-care protocol for colostomy patients on peri-stomal skin complications. Research design: Quasi-experimental research design was used to conduct this study. Setting: The study was conducted at General Surgical Department and Out Patients' Clinic at Benha University Hospital. Sample: Purposive sample of 60 adult patients from both gender with age ranging from 20 to 60 years old and have permanent stoma were involved in this study. Tools: Three tools were used in this study. I: A structured interviewing questionnaire. II: Self-care performance checklist and III: The peri-stomal skin DET assessment. Results: Less than half of the studied patients had satisfactory total knowledge regarding colostomy pre self-care protocol implementation which increased to three quarters post self-care protocol implementation, one third of them had satisfactory total self-care practices pre self-care protocol implementation which increased to $86.7 \%$ post self-care protocol implementation. Conclusion: The self-care protocol succeeded to improve the studied patients' knowledge and practices regarding colostomy as well as to reduce the severity of the peristomal skin complication. Recommendations: Further study should be carried out on the aspect of improving the colostomy patients' physical and psychological health as well as the patients' quality of life.
\end{abstract}

Key words: Colostomy patients, Peristomal skin complications, Self-care protocol.

\section{Introduction}

Colostomy is a surgically created opening in the abdomen in which a piece of the colon (large intestine) is brought outside the abdominal wall to create a stoma through which digested food passes into an external pouching system. A colostomy is created when a portion of the colon or rectum is removed due to a disease process (e.g. cancer) or damaged area of the colon and can be temporary or permanent (Canadian Cancer Society, 2021).

Stoma is an artificial opening where a luminal organ in the abdomen is mouthed to the abdominal wall by surgical intervention. Stoma also looks like a small, pinkish, circular piece of flesh that is sewn to the body and may lie fairly flat to the body or protrude out. Stoma is performed for the management of bowel dysfunction due to various causes that are not limited to cancer. Many other causes include acute diverticulitis, trauma or injury, imperforate anus, partial or complete intestinal blockage, inflammatory bowel disease (Yılmaz et al., 2021).

Like any surgical procedure, colostomy patients face many complications. Colostomy related complications may be local or systemic, may occur early or late, intermittently or progressively. Local complications includes bleeding, peristomal skin discoloration, erosion, stomal necrosis, 
tissue over growth, prolapse, retraction, stenosis, parastomal hernia, parastomal abscess and wound infection. Systemic complications are electrolytes imbalance, malnutrition, weight loss or even death may occur. Most of the complications can be prevented by adequate preoperative preparation, sound surgical technique and a better rehabilitation to prepare the patient psychologically (Haque et al., 2021).

The surgical nurses responsible for giving specific information to patients preoperative regarding the stoma and preparing patients psychologically. Post-operatively, the patients also provided with information and support from everyone involved in the care. After hospital discharge, the process of living as an intestinal stoma patient begins. This process can be favored with the teaching of individualized self-care, the use of devices and the clinical assistance to control complications, treatment, allowing the patients to fulfill their family, work and social duties and return to the relationships, activities, hobbies and improving life style is a very important goal in treating and caring for patients with colostomy (Fitzmorris \& Balart, 2021).

\section{Significance of study}

Colorectal Cancer (CRC) is the third most commonly diagnosed malignancy and the fourth leading cause of cancer-related deaths in both men and women in the world. Moreover, it is estimated that in 2020 approximately 147,950 new CRC cases have been diagnosed and 53,200 individuals died of the disease. Further, CRC burden is expected to increase by $60 \%$ to more than 2.2 million new cases and 1.1 million cancer deaths by 2030 (Shaukat et al., 2021).

Colorectal cancer is the 7 th commonest cancer in Egypt, representing 3.47\% of male cancers and $3 \%$ of female cancers. Colorectal cancer in Egypt has no age predilection and more than one third of tumors affects the young population. Screening with colonoscopy decreases the frequency and mortality of CRC (Elkeleny et al., 2021).

Patients with colostomy face huge problems in terms of need to receive suitable information to adapt them to this new situation. The nurse as an educator must focus on giving appropriate health teaching to patients with generous feedback and evaluation to promote teaching. Preoperative and postoperative colostomy patient education can facilitate adjustment, reduce complications, and improve overall quality of life (Abdelmohsen, 2020).

\section{Aim of the study}

This study aimed to evaluate the effect of educational self-care protocol for colostomy patients on peri-stomal skin complications.

\section{Research hypotheses}

Self-care protocol for colostomy patients would be effective on preventing peri-stomal skin complications.

\section{Subjects and methods \\ Research design}

Quasi -experimental research design was used to conduct this study.

\section{Setting}

This study was conducted at General Surgical department that consist of six rooms every room consist of 6 beds and Out Patients' Clinic at Benha University Hospital.

\section{Subject}

Purposive sample of 60 adult patients from both gender with age ranged from 20 to 60 years old and have permanent stoma were involved in this study after exclusion of 6 patients who included in pilot study. The sample included all the available patients for 6 months who were able to communicate and participate in the study. 


\section{Exclusion criteria}

People with end stage diseases and those who were suffering from physical, cognitive, mental and /or psychological disabilities that prevent them from participating in the educational self-care protocol.

\section{Tools of data collection}

Three tools were designed to collect the data of this study:

Tool I: A structured interviewing questionnaire It was adopted from (Ahmed et al., 2018), (Mohamed et al., 2017), and (Park, 2018) and modified by the researcher after reviewing the related and recent literature and included three parts:

Part I: The studied patients' sociodemographic characteristics.

This part was conducted to assess the studied patients' socio-demographic characteristics and included six closed ended questions related to age, sex, marital status, educational level, residence, and nature of work.

Part II: - The studied patients' medical history.

This part was developed to assess the studied patients' past and present medical history and included thirteen closed ended questions.

Part III: The studied patients' knowledge regarding colostomy.

This part was developed to assess the studied patients' knowledge regarding colostomy and included twenty closed ended (multiple choice) questions.

\section{Scoring system}

Each correct answer was scored as one score and each incorrect answer was scored as zero. The total score of all questions ranged from 0 to 22 scores. These scores were summed-up and converted into percent then categorized as the following:

- Knowledge scores $\geq 80 \%$ ( $\geq 16$ scores) considered satisfactory knowledge.
- Knowledge scores $<80 \%$ ( $<16$ scores) considered unsatisfactory knowledge.

\section{Tool II: - Self-care performance checklist} for colostomy:

This tool was adopted from (Gaber, 2017) and used to assess the studied patients' practices regarding colostomy care. It included forty five steps, 5 steps for removing the old pouch, 4 steps for cleaning the stoma and skin around stoma, 13 steps regarding applying the pouch, 5 steps for emptying the pouch, and 18 steps regarding colostomy irrigation. This part measured pre and post program.

\section{Scoring system}

Completely done $=2$

1 Incompletely done

0 Not done

The total score of practices ranged from 0 to 90 scores. These scores were summed-up and converted into percent then categorized as the following:

- Practices scores $\geq 80 \%$ ( $\geq 72$ scores) considered satisfactory practices.

- Practices scores < 80\% (72 scores) considered unsatisfactory practices.

\section{Tool III: The peri-stomal skin DET} assessment:

This tool was adopted from (Martins et al., 2015) and used to assess the extent of severity of the peristomal skin complication and included three items related to the discoloration area and severity, erosion area and severity, and tissue over growth area and severity (DET)

\section{Scoring system}

Assessment of discoloration was distributed to area of discoloration with scores ranged from 0 to 3 , severity of discoloration with score ranged from 0 to 2 with total score of discoloration ranged from 0 to 5 . Assessment of erosion was distributed to area of erosion with scores ranged from 0 to 3 and severity of erosion with scores ranged from 0 
to 2 with total score of erosion ranged from 0

to 5. Assessment of tissue over growth was distributed to area of tissue over growth with scores ranged from 0 to 3 and severity of tissue over growth with scores ranged from 0 to 2 with total score of tissue over growth ranged from 0 to 5 . The total DET assessment score ranged from 0-15.

These scores were summed-up and converted into percent then categorized to three levels of severity as the following:

- Mild = DET $<4$

- Moderate $=$ DET $\geq 4<7$

Severe $\quad=$ DET $\geq 7$

\section{Validity of the tools}

Content validity of the suggested tools was done by a jury of five experts in Medical Surgical Nursing department in Faculty of Nursing Benha University to determine whether the included items are clear and suitable to achieve the aim of the current study. Their opinions elicited regarding the format, layout, consistency, accuracy and relevancy of the tools.

\section{Reliability}

Reliability of the tools was done by using Cronbach's Alpha coefficient test which revealed that each of the three tools consisted of relatively homogenous items as indicated by high reliability for each tool. The internal consistency of the tools was as the following

\section{Tools Cronbach Alpha}

Structured interviewing questionnaire 0.91

Self care performance checklist for colostomy 0.88

The peristomal skin assessment $\quad 0.89$

\section{Ethical consideration:}

The ethical research considerations included the following:

- An oral consent was obtained from the studied patients in order to participate in the study.

- The aim of the study explained to all the patients and they were reassured that all the information will be confidential and it will be used only for their benefit and for the research purpose

- The studied patients were also informed that they are allowed to choose to participate or not in the study and they have the right to withdraw from the study at any time.

\section{Pilot study}

A pilot study was conducted on $10 \%$ from the total number of patients and they were excluded from the study. The pilot study was aimed to assess the feasibility, clarity, and applicability of the tools also to determine the time needed for filling the structured questionnaire. According to the results obtained from data analysis, the modifications, correction, omission and addition were done.

\section{Field work}

- The study was conducted over a period of 6 months which started from June 2020 to the end of November 2020; data were collected by interviewing the studied patients in the general surgical department and the out patients' clinic at Benha University Hospital.

- The researcher was attended to the general surgical department and the out patients' clinic two days/week (Saturday and Sunday) from 9:00 am to 12:00 md per day at morning shift to collect the data. The study was carried out through four phases.

- The researcher collected the studied patients' socio-demographic characteristics, the patients' medical history, and the patients' knowledge regarding colostomy using tool I. The investigator assessed the studied patients' performance regarding colostomy care using tool II.

- The researcher assessed the severity of 
peri-stomal skin complication using tool III

\section{Implementation of the self-care protocol:}

The researcher was attended to the general surgical department and the out patients' clinic two days/week (Saturday and Sunday) from 9:00 am to 12:00 md per day at morning shift to collect the data.

The number of sessions was five(4) sessions (2 sessions for theoretical part and 2 sessions for practical part). The duration of each session was 45 - 60 minutes, including the periods of discussion. The studied patients were present all the time of the sessions and the duration of each session was variable, according to its contents as well as the patients response.

An orientation to the educational self-care protocol and its process were presented. Each session started with a brief summary about what had been given through the previous session, then the objectives of the new topics, taking into consideration the use of simple language to suite the patients' level of education.

Discussion, motivation and reinforcement during the sessions were used to enhance learning. Direct reinforcement in a form of copy of the educational self-care protocol was given as a gift for each patient to use it as a future reference. All the patients were cooperative with the researcher and at the end of each session the patients participated in a discussion to correct any misunderstanding. Also, they were informed about the time of the next session.

\section{Evaluation of the self-care protocol:}

Evaluation of the educational self-care protocol was done immediately post implementation by using the same pre/post tools (I \& II) to evaluate the degree of improvement in the studied patients' knowledge, and performance regarding colostomy care. Also the peristomal skin complication was reassessed using tool III after two months of implementing self-care protocol.

\section{Statistical analysis}

Statistical analysis was done by using Statistical Package for Social Sciences (SPSS) version 22. Data were collected, revised, coded, organized, tabulated, and analyzed using frequencies, number, percentage, mean scores, standard deviation. Data were presented in the form of tables and figures. Qualitative data was presented in the form of frequency distribution tables, number and percent. It was analyzed by Chi- square test $\left(\mathrm{X}^{2}\right)$ to detect the relation between the variables of the study (P-value).

\section{Statistical significance was considered as follows: \\ - P-value > $0.05 \quad$ Not significant \\ - P-value $<0.05$ Significant \\ - P-value $<0.001$ Highly significant}

\section{Results}

Table (1): Shows that, $50.0 \%$ of studied patients aged between 40 to less than 50 year old with a mean age and standard deviation of $44.63 \pm 12.80$. In relation to sex and marital status, $53.3 \%$ \& $55.0 \%$ of them were males and widowed respectively. As well $40.0 \%$ of them were read and write, and $90.0 \%$ were living in rural areas. Concerning the nature of work, $55.0 \%$ of the studied patients had no work.

Figure (1): Indicates that, $40.0 \%$ of the studied patients had satisfactory total knowledge score regarding colostomy pre self-care protocol implementation which increased to $75.0 \%$ post self-care protocol implementation.

Figure (2): Indicates that, $33.30 \%$ of the studied patients had satisfactory total practice score regarding colostomy pre self-care protocol implementation which increased to $86.70 \%$ post self-care protocol implementation. 
Table (2): Clarifies that, $33.3 \%$ of the studied patients had an area of discoloration from 25-50 of the total adhesion area pre selfcare protocol implementation which decreased to $26.7 \%$ post self-care protocol implementation. While, $58.3 \%$ of them had mild discoloration pre self-care protocol implementation which decreased to $38.3 \%$ post self-care protocol implementation. Also, there were highly statistically significant differences between the peristomal skin discoloration pre and post self-care protocol implementation $(\mathrm{P}<0.001)$.

Table (3): Describes that, $35.0 \%$ of the studied patients had an area of erosion less than 25 of the total adhesion area pre selfcare protocol implementation which decreased to $25.0 \%$ post self-care protocol implementation. While, less $61.7 \%$ of them had an area which is not severely eroded pre self-care protocol implementation which decreased to $36.7 \%$ post self-care protocol implementation. Also, there were highly statistically significant differences between the peristomal skin erosion pre and post selfcare protocol implementation $(\mathrm{P}<0.001)$.

Table (4): Describes that, $41.7 \%$ of the studied patients had an area of tissue over growth less than 25 of the total adhesion area pre self-care protocol implementation which decreased to $26.7 \%$ post self-care protocol implementation. While, $60.0 \%$ of them had an area which is not severely overgrown pre selfcare protocol implementation which decreased to $31.7 \%$ post self-care protocol implementation. Also, there were highly statistically significant differences between the peristomal tissue over growth pre and post self-care protocol implementation $(\mathrm{P}<0.001)$.

Figure (3): Indicates that, $38.30 \%$ of the studied patients had sever skin complication pre self-care protocol implementation which decreased to $1.70 \%$ post self-care protocol implementation.

Table (5): Illustrates that, there was statistically significant positive correlation between the studied patients' total knowledge and total practices pre and post self-care protocol implementation $(\mathrm{P}<0.05)$.

Table (6): Illustrates that, there was highly statistically significant positive correlation between the studied patients' total knowledge and peristomal skin complication pre and post self-care protocol implementation $(\mathrm{P}<0.001)$.

Table (7): Illustrates that, there was highly statistically significant positive correlation between the studied patients' total self-care practices and peristomal skin complication pre and post self-care protocol implementation $\quad(\mathrm{P} \quad<\quad$ 0.001). 
Table 1: Frequency and percentage distribution of the studied patients according to their socio-demographic characteristics, $(n=60)$.

\begin{tabular}{lll}
\hline $\begin{array}{l}\text { Socio-demographic characteristics } \\
\text { Age: }\end{array}$ & No. & \% \\
20<30 years & 3 & 5.0 \\
$30<40$ years & 27 & 45.0 \\
$40<50$ years & 30 & $\mathbf{5 0 . 0}$ \\
$\overline{\mathbf{X}} \pm$ SD $44.63 \pm 12.80$ & & \\
Sex: & & \\
Male & 32 & $\mathbf{5 3 . 3}$ \\
Female & 28 & 46.7 \\
Marital status: & & \\
Married & 27 & 45.0 \\
Widow & 33 & $\mathbf{5 5 . 0}$ \\
Educational level: & & \\
Illiterate & 9 & 15.0 \\
Read and write & 24 & $\mathbf{4 0 . 0}$ \\
Secondary learning & 21 & 35.0 \\
High education & 6 & 10.0 \\
Residence: & & \\
Rural & 54 & $\mathbf{9 0 . 0}$ \\
Urban & 6 & 10.0 \\
Nature of work: & & \\
Need mind effort & 20 & 33.3 \\
Needs muscular efforts & 7 & 11.7 \\
There is no work & 33 & $\mathbf{5 5 . 0}$ \\
\hline
\end{tabular}

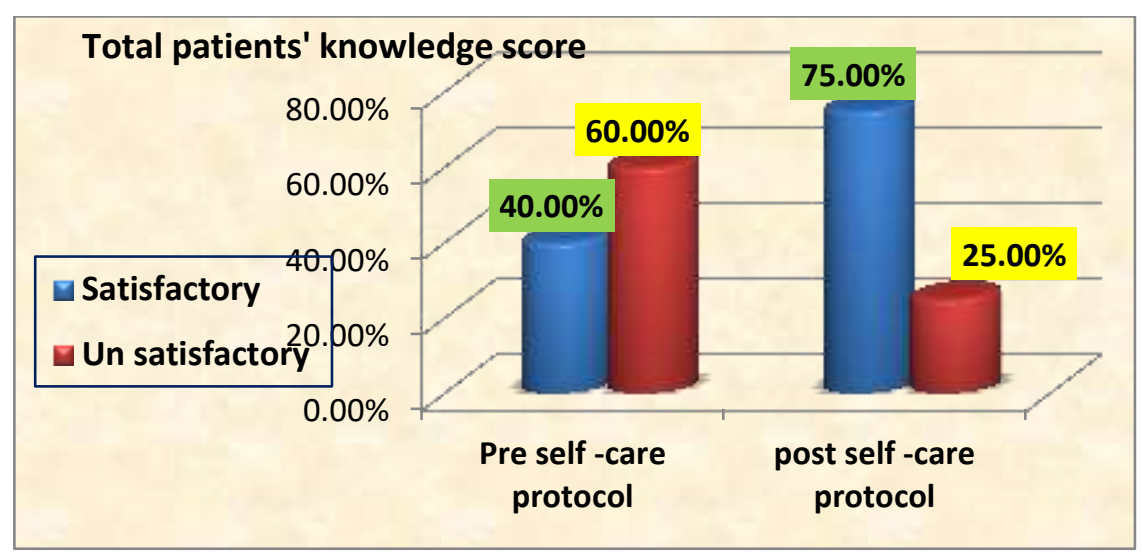

Figure 1: Percentage distribution of studied patients' total knowledge score regarding colostomy pre and post self-care protocol implementation, $(n=60)$

\section{Total patients'practice score}

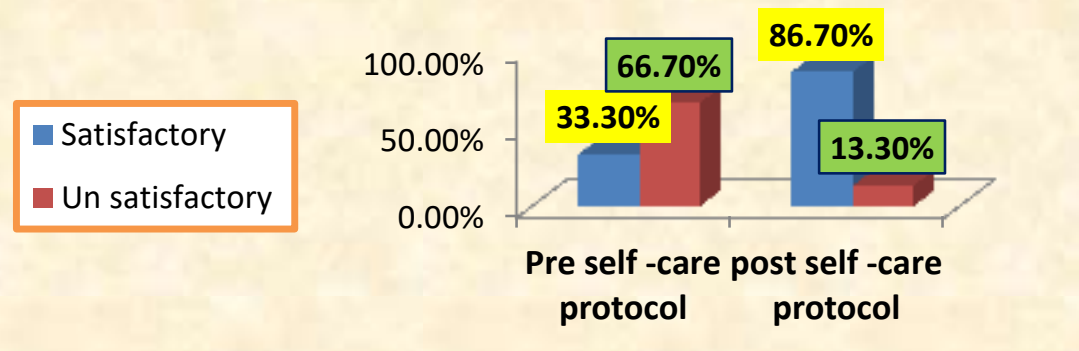

Figure 2: Percentage distribution of the studied patients according to their total self-care practices score pre and post self-care protocol implementation, $(n=60)$ 
Table 2: Frequency and percentage distribution of the studied patients according to their peristomal skin discoloration pre and post self-care protocol implementation, $(n=60)$.

\begin{tabular}{|c|c|c|c|c|c|c|}
\hline \multirow{2}{*}{ The peristomal skin discoloration } & \multicolumn{2}{|l|}{ Pre } & \multicolumn{2}{|c|}{ Post } & \multicolumn{2}{|c|}{ Significance test } \\
\hline & No. & $\%$ & No. & $\%$ & $\chi^{2}$ & P-value \\
\hline A- Area of discoloration: & & & & & & \\
\hline $\begin{array}{l}\text { There is no area of } \\
\text { discoloration. }\end{array}$ & 7 & 11.7 & 3 & 5.0 & & \\
\hline The area of discoloration is & 18 & 30.0 & 31 & 51.6 & & \\
\hline less than 25 of total adhesion area. & & & & & 22.45 & $0.001 * *$ \\
\hline $\begin{array}{l}\text { The area of discoloration is } 25- \\
50 \text { of total adhesion area. }\end{array}$ & 20 & 33.3 & 16 & 26.7 & & \\
\hline $\begin{array}{l}\text { - The area of discoloration is } \\
\text { over } 50 \text { of total adhesion area. } \\
\text { B- Severity of discoloration: }\end{array}$ & 15 & 25.0 & 10 & 16.7 & & \\
\hline As there is no adhesion. & 10 & 16.7 & 27 & 45.0 & & \\
\hline The area is mild discolored. & 35 & 58.3 & 23 & 38.3 & 30.17 & $0.001 * *$ \\
\hline $\begin{array}{l}\text { The area is severely } \\
\text { discolored. }\end{array}$ & 15 & 25.0 & 10 & 16.7 & & \\
\hline
\end{tabular}

Table 3: Frequency and percentage distribution of the studied patients according to the peristomal skin erosion pre and post self-care protocol implementation, $(n=60)$.

\begin{tabular}{llllll}
\hline The peristomal skin erosion & Pre & Post & \multicolumn{2}{c}{ Significance test } \\
& No. $\%$ & No. & $\%$ & $\chi^{2}$ & P-value
\end{tabular}

A- Area of erosion:

$\begin{array}{llllllll}\text { - } & \text { There is no evidence of } & 14 & 23.3 & 31 & 51.7\end{array}$ erosion.

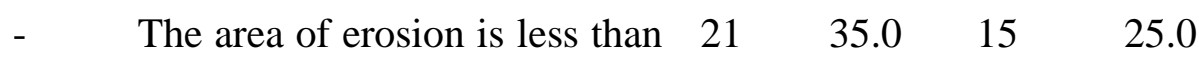

25 of total adhesion area.

$33.98 \quad 0.001 * *$

$\begin{array}{llllll}- & \text { The area of erosion is } 25-50 \text { of } & 16 & 26.7 & 10 & 16.7\end{array}$

total adhesion area.

$\begin{array}{llllll}- & \text { The area of erosion is over } 50 & 9 & 15.0 & 4 & 6.6\end{array}$

of total adhesion area.

\section{B- Severity of erosion:}

- $\quad$ As there is no erosion there is $\begin{array}{llll}14 & 23.3 & 30 & 50.0\end{array}$ no severity.

$\begin{array}{llllllllll}\text { - } & \text { The area } \text { is not severely } & 37 & 61.7 & 22 & 36.7 & 19.56 & 0.001 * *\end{array}$ eroded.

$\begin{array}{llllll}- & \text { The area is severely eroded. } & 9 & 15.0 & 8 & 13.3\end{array}$ 
Table 4: Frequency and percentage distribution of the studied patients according to the peristomal tissue over growth pre and post self-care protocol implementation, $(n=60)$.

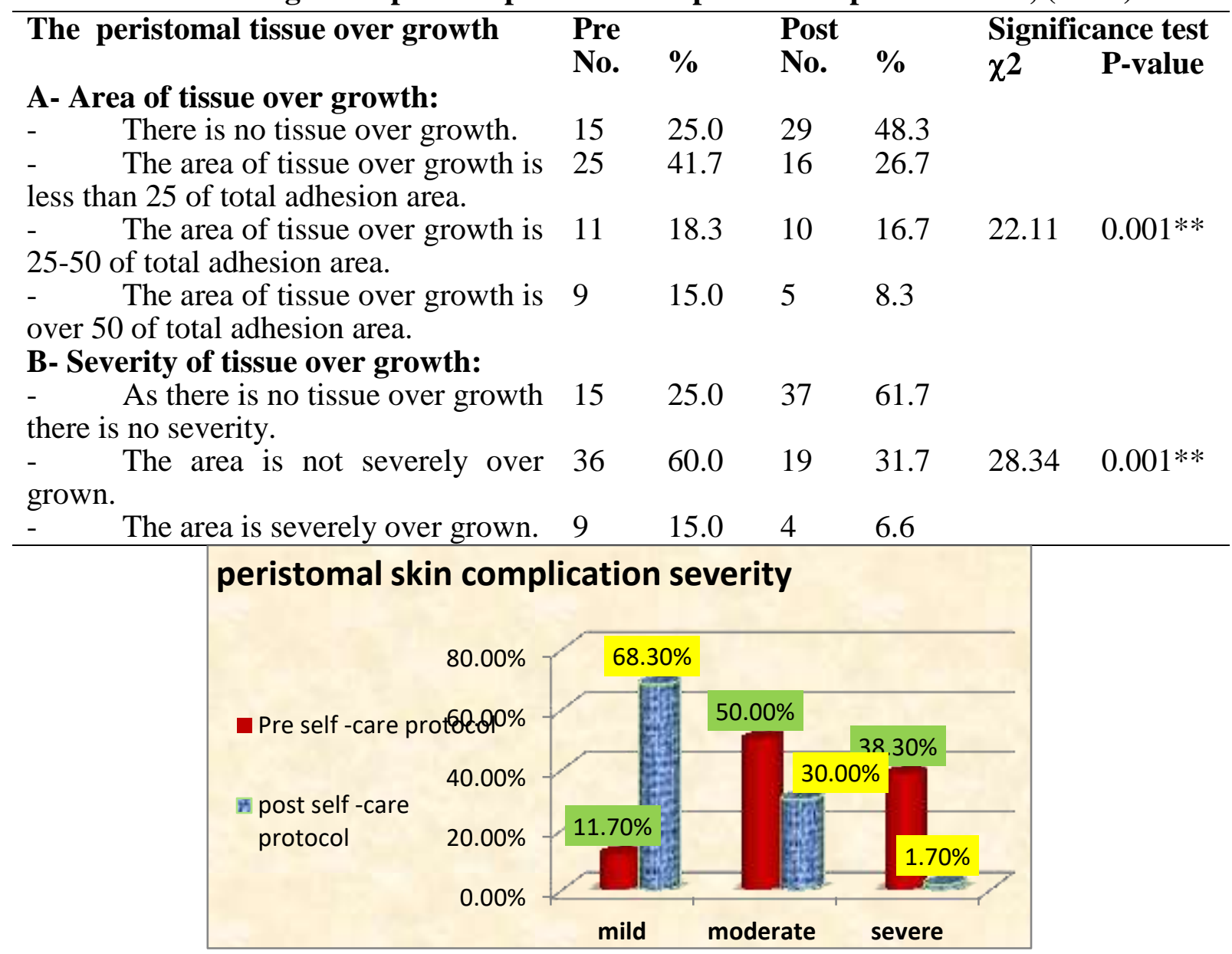

Figure (3): Percentage distribution of the studied patients according to their peristomal skin complication severity pre and post self-care protocol implementation, $(n=60)$

Table (5): Correlation between the studied patients' total knowledge and total practices regarding colostomy care pre and post self-care protocol implementation, $(n=60)$.

\begin{tabular}{lllll}
\hline Items & \multicolumn{2}{l}{ Total knowledge } & \multicolumn{1}{l}{ Post } & \\
& Pre & P-value & r & P-value \\
Total practices & R & $0.003^{*}$ & 0.282 & $0.029^{*}$ \\
\hline
\end{tabular}

Table (6): Correlation between the studied patients' total knowledge and peristomal skin complication pre and post self-care protocol implementation, $(\mathrm{n}=60)$.

\begin{tabular}{lllll}
\hline Items & \multicolumn{3}{l}{ Total knowledge } & \\
& Pre & Post & \\
Peristomal skin complication & $\mathbf{R}$ & P-value & r & P-value \\
& 0.557 & $0.001 * *$ & 0.399 & $0.001 * *$ \\
\hline
\end{tabular}

Table (7): Correlation between the studied patients' total self-care practices and peristomal skin complication pre and post self-care protocol implementation, $(n=60)$.

\begin{tabular}{lllll}
\hline Items & \multicolumn{3}{l}{ Total self-care practices } & \\
& Pre & & Post & \\
Peristomal skin complication & $\mathbf{R}$ & P-value & $\mathbf{r}$ & P-value \\
& 0.444 & $0.001 * *$ & 0.290 & $0.001^{*}$ \\
\hline
\end{tabular}




\section{Discussion}

Regarding age; the current study showed that, half of studied patients aged between 40 to less than 50 year old. This result might be due to this is the most commonly affected age with colon cancer. This result agreed with (Wong etal 2015), who studied a "systematic review recommends the European organization for research and treatment of cancer colorectal cancer-specific module for measuring quality of life in colorectal cancer patients", and found that half of the studied patients aged between 40 to less than 50 year old. This result also agreed with (Fernades \&Brito (2020), who conducted a study about "effect of a stoma nursing care program on the adjustment of patients with an ostomy in Colombia", and found that more than half of the studied patients aged between 40 to less than 50 years old.

The same result disagreed with (Abdel mohesen 2020), who conducted a study about "effectiveness of structured education on patient's knowledge and practice regarding colostomy care at south Egypt cancer institute in Assiut", and found that more than half of the studied patients aged between 14 to 35 year old.

As regards the patients' sex and marital status; the current study showed that more than half of the studied patients were males, and they were also widowed. These results might be because most of men are heavy smokers and had fast food and these factors increase the risk of developing colorectal cancer. These results agreed with (Hagazy et al 2014), who conducted a study about "outcomes of educational guidelines on awareness and self-efficacy among patients with permanent colostomy in Cairo", and found that more than half of the studied patients were males and they were also widowed. These findings also disagreed with (Kadom \&Shind 2014), who performed a study about "effectiveness of structured education on caregiver's knowledge and attitude regarding colostomy care in India", and found that two thirds of the studied patients were females and they were married.

Regarding the studied patients' educational level; the study result showed that two fifths of the studied patients were read and write. This result might be because the most of patients live in rural area with less attention to education. This result agreed with (Mohamed et al 2017), whose study was about "effect of self-care management program on self-efficacy among patients with colostomy at Benha teaching hospital", and found that the highest percentage of the sample had basic education.

The same result disagreed with (Ran et al 2016), whose study was about" quality of life, self-care knowledge access, and self-care needs in patients with colon stomas one month post-surgery in a Chinese tumor hospital " and found that the majority of the studied patients had secondary education. This result also disagreed with (El sayed et al 2018), whose study was about "effect of nursing stoma care training on geriatric patients' self-esteem and psychological status in Egypt", and found that less than half of the studied patients were illiterate .

Concerning the residence, and nature of work; the present study findings denoted that most of the studied patients were living in rural areas, and more than half of them had no work. These findings might be because of the fatigability which consider the main feature of physical limitation postoperatively or because of the bad psychological condition that the patients have. These findings were in the same line with (Fernandes \&Brito 2020), who found that the majority of the studied patients were living in rural areas, and more than half of them were retired.

The same findings disagreed with (Abd el Rahman et al 2020), whose a study was about "effect of nursing 
instructions on self-care for colostomy patients at Assiut university hospital", and found that more than half of the studied patients were working, while agreed with them as they found that slightly less than two thirds of the studied patients were living in rural areas.

This result was in the same line with (Sousa et al. (2016), who developed a study about "socio-demographic and clinical features and quality of life in stomized patients in Brazil", and found that less than half of the studied patients had good total knowledge regarding colostomy preprogram which increased to more than three quarters post program. The same result disagreed with Martins et al. (2015), whose study was about "the ostomy skin tool: tracking peristomal skin changes in England", and found that there was slightly improvement in the studied patients' total knowledge regarding colostomy in post program.

In relation to the studied patients' total self-care practices score pre and post self-care protocol implementation; the study results showed that only one third of the studied patients had satisfactory level of selfcare practices pre self-care protocol implementation which increased to include most of them post self-care protocol implementation. This might be because of the effectiveness of the self-care protocol.

This result was in the same line with Mohamed et al. (2012), who performed a study about "assessment of quality of life for patients with colostomy post colorectal surgery in Egypt", and found that only one third of the studied patients had satisfactory level of self-care practices pre-program which significantly improved to include more than three quarters of them post program. This result was also in the same line with Hegazy et al. (2014), who reported that the majority of the studied subjects had a weak total level of self-care practices. Meanwhile post program there was significant improvement of the practices.

Concerning the studied patients' peristomal skin discoloration pre and post self-care protocol implementation; the present study findings clarified that one fourth of them had an area of discoloration more than 50 of the total adhesion area pre self-care protocol implementation which decreased to include less than one fifth post self-care protocol implementation. This might be because of the effectiveness of the self-care protocol. Also, there were highly statistically significant differences between the peristomal skin discoloration pre and post self-care protocol implementation $(\mathrm{P}<0.001$. (

These findings were in the same line with (Alenezi\&Mansour 2016), who reported that more than half of the studied patients had an area of discoloration from 25-50 of the total adhesion area which improved to include less than one fifth after the program implementation. These findings were also in the same line with (Qalawa \&Mousa 2019), who performed a study about "effectiveness of a multimedia educational package for cancer patients with colostomy on their performance, quality of life \& body image in Egypt", and found that there were highly statistically significant differences found between the studied patients' peristomal skin discoloration pre and post educational package implementation $(\mathrm{P}<0.001$. (

Regarding the studied patients' peristomal skin erosion pre and post self-care protocol implementation; the present study results described that, more than one fourth of the studied patients had an area of erosion from 25-50 of the total adhesion area pre self-care protocol implementation which decreased to include one fifth post self-care protocol implementation. This might be because of the effectiveness of the self-care protocol. Also, there were highly statistically significant differences between the peristomal skin 
erosion pre and post self-care protocol implementation $(\mathrm{P}<0.001$. (

These results were in the same line with (Seo 2019), who performed a study about "effects of the frequency of ostomy management reinforcement education on selfcare knowledge, self-efficacy, and ability of stoma appliance change among Korean hospitalised ostomates", and found that nearly to three quarters of the studied patients had an area of erosion less than 25 of the total adhesion area before the educational self-care implementation which decreased to less than one third after the educational self-care implementation. While, slightly less than half of them had a severely eroded area before the educational self-care implementation which decreased to less than one fourth after the educational self-care implementation.

These results were also similar to (Pouresmail et al 2019), who performed a study about "effect of using a simulation device for ostomy self-care teaching in Iran", and found that there were highly statistically significant differences between the patients' peristomal skin erosion before and after the educational self-care implementation $(\mathrm{P}<0.00$

In relation to the studied patients' peristomal tissue over growth pre and post self-care protocol implementation; the present study described that more than two fifths of the studied patients had an area of tissue over growth less than 25 of the total adhesion area pre self-care protocol implementation which decreased to include slightly more than one fourth post self-care protocol implementation. This might be because of the effectiveness of the self-care protocol. Also, there were highly statistically significant differences between the peristomal tissue over growth pre and post self-care protocol implementation $(\mathrm{P}<0.001)$. These results disagreed with (Ahmed et al 2018), who found that the entire study group didn't have any tissue overgrowth. The same results also disagreed with (Alenezi \&Mansour 2016), who found that among the study group, there were a decrease in peristomal skin complications.

As regards the studied patients' peristomal skin complication severity pre and post self-care protocol implementation; the present study results described that half of the studied patients had moderate peristomal skin complication pre self-care protocol implementation which decreased to less than one third post two months of self-care protocol implementation, while more than one third of them had sever peristomal skin complication which decreased to include the minority of them post two months of self-care protocol implementation. This might be because the program succeeded to improve the studied patients' practices towards peristomal skin care which in turn lead to decrease complication.

This result agreed with Stelton (2019), whose study was about "effect of educational program on patients' with permanent colostomy regarding stoma and peristomal skin care in Brazil", and found that two thirds of the studied patients had moderate peristomal skin complication pre-program which decreased to less than one fifth post program.

Concerning the relation between the studied patients' total knowledge score and their socio-demographic characteristics pre and post self-care protocol implementation; the present study findings described that there were highly statistically significant relations between the studied patients' total knowledge score and their age, marital status, and educational level $(\mathrm{P}<0.05)$ pre and post selfcare protocol implementation. Also, there were statistically significant relations between the studied patients' total knowledge score and their sex, and nature of work $(\mathrm{P}<0.05)$ pre self-care protocol implementation. This might be because some of the socio-demographic variables such as age, and educational level 


\section{$\underline{\text { Effect of Self Care Protocol for Colostomy Patients on Peristomal Skin Complications }}$}

usually affect the knowledge level of any person.

These findings were in the same line with (Poonguzhali \&Nagendran 2016), whose study was about "effectiveness of instructional package on knowledge regarding colostomy care among adult patients in postoperative ward at Madurai", and found that the studied patients' knowledge level was statistically affected by the patients' age, sex, marital status, education, and work. The same findings disagreed with (Liao \&Qin 2014), who carried out a study about "factors associated with stoma quality of life among stoma patients in Beijing", and found that there were highly statistically significant relations found between the studied patients' total level of knowledge as well as their total quality of life and their age, educational level, and residence, while there were no other relations found.

Regarding the relation between studied patients' total self-care practices and their socio-demographic characteristics pre and post self-care protocol implementation; the present study clarified that there were statistically significant relations between the studied patients' total self-care practices and their marital status and educational level pre and post self-care protocol implementation $(\mathrm{P}<0.05)$. While there were a statistically significant relations between the studied patients' total self-care practices and their sex, and nature of work post self-care protocol implementation only $(\mathrm{P}<0.05$. (

These results were in the same line with (Pandey et al 2015), who found that there were highly statistically significant relations between the studied patients' self-care practices and their socio-demographic characteristic except in residence and occupation. But these results were against the results of (Sabea \&Shaqueer 2019), who conducted a study about "effect of self-care program for patients using colostomy at
Mansoura city", and found that there were no statistically significant relations found between the studied patients' total self-care practices and their socio-demographic characteristics except in age, and educational level pre and post program.

Regarding the correlation between the studied patients' total knowledge and total practices regarding colostomy care pre and post self-care protocol implementation; the present study finding illustrated that there was statistically significant positive correlation between the studied patients total knowledge and total practices pre and post self-care protocol implementation $(\mathrm{P}<0.05)$. This might be related to the fact that knowledge is the base for acquiring practical skills.

This finding supported by (Stokes et al 2017), whose study entitled "institution of a preoperative stoma education group class decreases rate of peristomal complications in new stoma patients in the United States", and found that there was statistically significant positive correlation between the studied patients total knowledge and total practices pre and post program. This result was also consistent with (Almanzalawi 2020), whose study was about "effect of self-management program on the patient' knowledge and practice regarding stoma care in Egypt", and found that there was highly statistically significant positive correlation between the studied patients' knowledge and practices regarding stoma care between pre and post program $(\mathrm{P}<0.001$. (

Concerning the correlation between the studied patients' total knowledge and peristomal skin complication pre and post self-care protocol implementation; the present study result illustrated that there was highly statistically significant positive correlation between the studied patients' total knowledge and peristomal skin complication pre and post self-care protocol implementation $(\mathrm{P}<0.001)$. This might be because the improving level of 
knowledge positively affects the patients' level of practice hence being able to reduce the incidence of peristomal skin complication. This result was in the same line with (Culha et al 2016), who found a positive correlation between the studied patients' knowledge scores and peristomal skin complication $(\mathrm{P}<0.001)$.

Concerning the correlation between the studied patients' total self-care practices and peristomal skin complication pre and post self-care protocol implementation; the present study result illustrated that there was highly statistically significant positive correlation between the studied patients' total self-care practices and peristomal skin complication pre and post self-care protocol implementation $(\mathrm{P}<0.001)$. This might be because the improving level of practiceregarding peristomal care usually reflects a good peristomal skin condition. This result agreed with (Harputlu\&Ozso 2018), whose study entitled "a prospective, experimental study to assess the effectiveness of home care nursing on the healing of peristomal skin complications and quality of life. ostomy/wound management in Turkey", and found that there was statistically significant positive correlation between the studied patients' total self-care practices and peristomal skin complication pre and post home care nursing intervention $(\mathrm{P}<0.001$ (

\section{Conclusion}

The self-care protocol succeeded to improve the studied patients' knowledge and practices regarding colostomy as well as to reduce the severity of the peristomal skin complication, (discoloration, erosion, tissue over growth).

\section{Recommendations}

- The study should be replicated to include a large and randomly selected sample size.

- Planned self-care educational protocol should be conducted by a colostomy care team to prevent complications after patients' discharge.

- Further study should be carried out on the aspect of improving the colostomy patients' physical and psychological health as well as the patients' quality of life.

- Further study should be carried out on the aspect of the effect of colostomy on the patients' activities of daily life

\section{References}

Abd El-Rahman, W., Mekkawy, M., Sayed, S., \& Ayoub, M. (2020). Effect of Nursing Instructions on Self Care for Colostomy Patients at Assiut University Hospital. Assiut Scientific Nursing Journal; 8(23): Pp. 96-105.

Abdelmohsen, S. (2020). Effectiveness of Structured Education on Patient's Knowledge and Practice Regarding Colostomy Care at South Egypt Cancer Institute in Assiut. Asia-Pacific Journal of Oncology Nursing; 7(4): Pp. 370-374. doi: 10.4103 lapjon-24-20

Ahmed, M., Mohammed, E., Tohamy, T., \& Mohammed, J. (2018). Effect of A Designed Nursing and Patients Self Care Protocol on Reducing the Colostomy and Peristom al Complication among the Elderly Patients. Minia Scientific Nursing Journal; 4(1): Pp.68-75

Alenezi, A., \& Mansour, E. (2016). Impact of Stoma Care Education in Minimizing the Incidence of Stoma Skin Complications. Bahrain Medical Bulletin; 38(3):Pp. 151 153. DOI: $10.12816 / 0047489$ Corpus.

Almanzalawy, H. (2020). Effect of SelfManagement Program on the Patient'Knowledge and Practice Regarding Stoma Care. Assiut Scientific Nursing Journal, 8(23.00), 55-66.

Canadian Cancer Society, (2021).

Colostomy and ileostomy.Available at https://www.cancer.ca/eancer-

information/diagnosis-and-treatment/tests-and procedures/colostomy-and-

ileostomy/?region=sk. Accesse 
Collado-Boira, E., Machancoses, F., FolchAyora, A., Salas-Medina, P., Bernat-Adell, M., Bernalte-Martí, V., \& TempradoAlbalat, M. (2021). Self-Care and HealthRelated Quality of Life in Patients with Drainage Enterostomy: A Multicenter, Cross Sectional Study. International Journal of Environment and Research. Public Health 2021 18 , 2443. https://doi.org/10.3390/ijerph18052443. Culha, I., Kosgeroglu, N., \& Bolluk $O$. (2016). Effectiveness of Self-care Education on Patients with Stomas. Journal of Nursing and Health Science; 5 (2): Pp.70-76. DOI: 10.9790/1959-05217076

El Sayed, S., Abd Elhameed, S., Hassanen, A. (2018). Effect of nursing stoma care training on geriatric patients' self-esteem and psychological status. Journal of Nursing and Health Science; 7(4): Pp. 52-62. DOI: 10.9790/1959-0704085262.

Elkeleny, M., Abdelbaki, T., Sabry, A., \& Sharaan, M. (2021). Colonoscopy screening in early detection of colorectal cancer in highrisk groups: a prospective study. The Egyptian Journal of Surgery; 40(1): Pp. 3-10. DOI: 10.4103/ejs.ejs_129_20.

Fernandes, C., \& Brito, C. (2020). Effect of a Stoma Nursing Care Program on the Adjustment of Patients with an Ostomy; 20(1): P. e2014. DOI: https://doi.org/10.5294/aqui.2020.20.1.4.

Fitzmorris, P., \& Balart, C. (2021). Colon Cancer Awareness Month 2021. Available at: https://batonrougeclinic.com/colon-cancerawareness-month-2021/. Accessed on 2July 2021.

Gaber,H.,(2017).Astudyto identify the level of knowledge and self performance of colostomypatients and its effect on their qualityof life, The New Egyotian journals of medicine, 38(5).

Ginger, S., Janice, C., George, S., \& Joyce, P. (2020). Lessons Learned about Peristomal Skin Complications. Journal of Wound
Ostomy and

ContinenceNursing;47(4):Pp.357-363.doi: 10.1097/WON.0000000000000666.

Haque, M., Alam, S., Rahman, A., Khan, M., \& Haque, M. (2021). Surgical Outcomes of Temporary Ileostomy Patients attended at a Tertiary Care hospital in Dhaka City. Journal of Current and Advance Medical Research; 8(1):Pp.65-69.DOI:

https://doi.org/10.3329/jcamr.v8i1.52742

Harputlu, D., \& Ozso, S. (2018). A Prospective, Experimental Study to Assess the Effectiveness of Home Care Nursing on the Healing of Peristomal Skin Complications and Quality of Life. Ostomy/wound Management; 64(10):Pp.18-30.

DOI:10.25270/owm.2018.10.1830.

Hegazy, S., Ali, Z., Mahmoud, A., \& Abou-Zeid, A: (2014). Outcomes of Educational Guidelines on Awareness and Self-Efficacy among Patients with Permanent Colostomy. New York Science Journal; $\quad 7(3)$ : Pp.25-32. http://www.sciencepub.net/newyork.

Kadam, A., \& Shinde, M. (2014). Effectiveness of Structured Education on Cancer Patients' Knowledge, Attitude and Practices Regarding Colostomy Care. International Journal of Science and Research; 3(4): Pp. 591j

Liao, C., \& Qin, Y. (2014). Factors associated with stoma quality of life among stoma patients. International Journal of Nursing Sciences; 1(2): Pp.196-201. https://doi.org/10.1016/j.ijnss.2014.05.007.

Linda, B., \& Brenda, E. (2021). Colostomy Care: A Guide for Home Care Clinicians.Availableat:https://www.nursingce nter.com/ce_articleprint?an $=01845097$ -

201903000-00002. Accessed on 2 July 2021. n.vol.2,pp.12-18,2021.

Martins, L., Ayello, E., Claessens, I., Hansen, A., Poulsen, L., Gary Sibbald, R., \& Jemec, G. (2015). The Ostomy Skin Tool: Tracking Peristomal Skin Changes. 
British journal of nursing; 19(15): Pp.959964.

Mohamed, E., Abou-Zeid, A., Hegazy, S., \& Hamdi, A. (2012). Assessment of Quality of Life for Patients with Colostomy Post Colorectal Surgery, unpublished Master thesis, Ain Shams University, p.106.

Mohamed, S., Salem, G., \& Mohamed, H. (2017). Effect of Self-care Management Program on Self-efficacy among Patients with Colostomy. American Journal of Nurses Research; 5(2): Pp.191-9. DO: 10.12691/ajnr5-5-5.

Pandey, R., Baral, S., \& Dhungana, S. (2015). Knowledge and Practice of Stoma Care among Ostomies at Memorial Cancer Hospital. Journal of Nobel Medical College, 4(1), Issue 7, 36-45.

Park S. (2018). Disease of colon and rectum ,volume 58, The American socity of colon and rectal under operation

Poonguzhali, S., Poonguzhali, N., Nagendran, N. (2016). Effectiveness of Instructional Package on Knowledge regarding Colostomy Care among Adult Patients in Post-operative Ward at Madurai. Available at: https://core.ac.uk/download/pdf/235656078.p df. Accessed on 22 March 2021.

Pouresmail, Z., Nabavi, F., Abdollahi, A., Shakeri, M., \& Saki, A. (2019). Effect of Using a Simulation Device for Ostomy Selfcare Teaching in Iran: A Pilot, Randomized Clinical Trial. Wound Management Prev; 65(6): Pp.30-39. DOI:10.25270/wmp.2019.6.3039.

Qalawa A., \& Moussa, M. (2019). Effectiveness of a Multimedia Educational Package for Cancer Patients with Colostomy on Their Performance, Quality of Life \& Body Image. International Journal of Nursing Science; 9(3): Pp. 53-64.

Sabea, M., \& Shaqueer, T. (2019). Effect of Self-care Program for Patients Using Colostomy at Mansoura City. Available at: https://ejournal.lucp.net/index.php/mjn/article /view/1282/1351. Accessed on 22 March 2021.

Seo, H. (2019). Effects of the frequency of ostomy management reinforcement education on self-care knowledge, self-efficacy, and ability of stoma appliance change among Korean hospitalised ostomates. International Wound Journal; 16(1): Pp.21-28. DOI: 10.1111/iwj.13047.

Ran, L., Jiang, X., Qian, E., Kong, H., Wang, X., \& Liu, Q. (2016). Quality of life, self-care knowledge access, and self-care needs in patients with colon stomas one month post-surgery in a Chinese Tumor Hospital. International journal of nursing sciences, 3(3), 252-258.

Shaukat, A., Charles, J., Carol, A., Linda, R., Bryan, G., \& Douglas, K. (2021). ACG Clinical Guidelines: Colorectal Cancer Screening 2021. The American Journal of Gastroenterology; 116 (3): Pp. 458-479. doi: 10.14309/ajg.0000000000001122.

Sousa, M., Andrade, S., Brito, K., Matos, S., Coelh, S., \& Oliveira, S. (2016). Sociodemographic and Clinical Features and Quality of Life in Stomized Patients. Journal of coloproctol; 36(1): Pp.2733.

https://doi.org/10.1371/journal.pone.0247078.

Stelton ,S. (2019). Effect of Educational Program on patients with permanent colostomy Regrading stoma and peristomal skin care in Brazil AMJ Nurse ;119(6):pp3845

.Doi:

10.1097\01.NAJ.0000559781.86311.6.

Stokes, A., Tice, S., Follett, S., Paskey, D., Abraham, L., Bealer, C., Keister, H., Koltun, W., \& Puleo, F. (2017). Institution of a Preoperative Stoma Education Group Class Decreases Rate of Peri-stomal Complications in New Stoma Patients. Journal Wound Ostomy Continence Nursing, 44(4), 363-367. doi: 10.1097/WON.0000000000000338. 
Wong, C., Chen, J., Charlotte, L., Sham, M., \& Lam, C. (2015). Systematic Review Recommends the European Organization for Research and Treatment of Cancer Colorectal Cancer-specific Module for Measuring Quality of Life in Colorectal Cancer Patients. Journal of Clinical Epidemiology; 68 (3): Pp.266-278. doi: 10.1016/j.jclinepi.2014.09.021

Yılmaz, G., Harputlu, D., Pala, M., Mert, T., Çakıt, H., Sücüllü, I., \& Kuzu, A. (2021). A Cross Sectional Evaluation of Patients with Ostomy in Turkey. Turkish Journal of Colorectal Diseases; 31(2): Pp.136142. DOI:10.4274/tjcd.galenos.2020.2020$10-10$. 


\section{تاثير بروتوكول الرعاية الأتية لمرضي الفتحة القولونية علي مضاعفات الجلا}

$$
\text { امل محمد محمد سالم توحيد- منال حامد محمود- راوية علي ابر اهيم }
$$

تعرف الفتحة القولونية بأنها إجراء جراحي يتم فيه قطع ممر الأمعاء الطبيعي بفتحة أخري صناعية مؤقتة أو

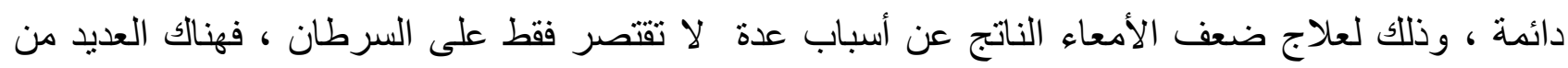

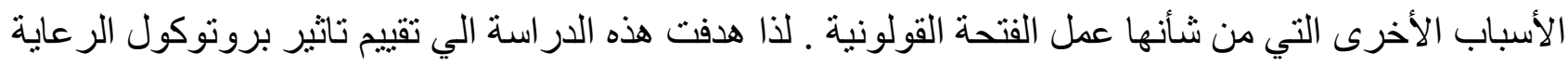
الذاتية لمرضي الفتحة القولونية علي حدوث المضاعفات المرتبطة بالجلا. وقد اجريت الدراسة في العيادات

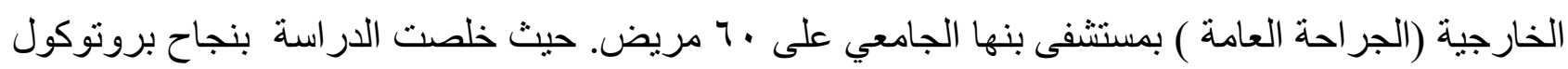

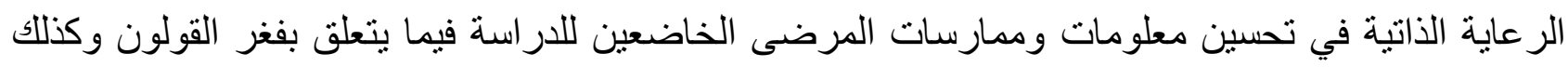

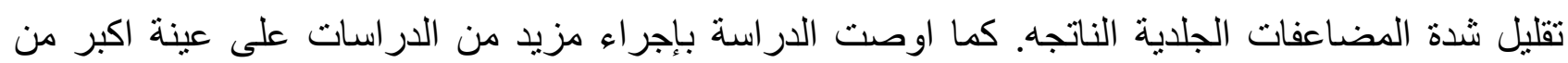
مرضى الفتحه القولونيه وذللك لتحسين حالتهم الجسمانيه وجودة حياتهم . 